\title{
Criação de personas para delinear o perfil de alunas de cursos de graduação de TI e direcionar ações para o fortalecimento e empoderamento feminino
}

\author{
Rhenara Alves Oliveira \\ Universidade Federal do Ceará \\ Russas-CE, Brasil \\ rhenaraalves21@alu.ufc.br
}

\author{
Karina Castelo Branco \\ Universidade Federal do Ceará \\ Russas-CE, Brasil \\ karinascb@alu.ufc.br
}

\author{
Anna Beatriz Marques \\ Universidade Federal do Ceará \\ Russas-CE, Brasil \\ beatriz.marques@ufc.br
}

\begin{abstract}
RESUMO
O uso de personas permite obter uma visão das principais características de um público alvo e é amplamente utilizado na proposta de novos produtos e serviços. Esta pesquisa propõe o uso de personas para direcionar a realização de ações de incentivo à permanência e engajamento de alunas nos cursos de TI da Universidade Federal do Ceará no campus de Russas. Foi realizada uma pesquisa baseada em questionário com as alunas do campus para identificar o seu perfil. Com base nos resultados foram criadas três personas. As personas descrevem o perfil das alunas, as problemáticas enfrentadas e fatores de risco que podem acarretar em sua desistência. A partir dos resultados, será possível definir ações a serem realizadas para $o$ fortalecimento $e$ empoderamento das alunas, criando assim uma maior participação feminina nos cursos de TI.
\end{abstract}

\section{Palavras-chave}

Personas; questionários; empoderamento feminino.

\section{ACM Classification Keywords}

Social and professional topics $\rightarrow$ User characteristics.

INTRODUÇÃO E CARACTERIZAÇÃO DO PROBLEMA Personas são arquétipos de usuários que servem como exemplo para representar o público alvo, ou seja, a quem o sistema se designa [4]. Trata-se da criação de personagens fictícios, que representam por meio de suas características o público-alvo do tema que se quer abordar.

Ações de incentivo para a inserção e permanência das mulheres na Computação vêm sendo adotadas por diversas universidades, empresas e instituições de fomento [1]. Entretanto, diferentes ações podem ser adotadas de acordo com os problemas e as necessidades identificadas em um determinado contexto, como oficinas, palestras, fóruns e competições. Nem toda ação pode ser adequada/necessária a

Permission to make digital or hard copies of all or part of this work for personal or classroom use is granted without fee provided that copies are not made or distributed for profit or commercial advantage and that copies bear this notice and the full citation on the first page. Copyrights for components of this work owned by others than the author(s) must be honored. Abstracting with credit is permitted. To copy otherwise, or republish, to post on servers or to redistribute to lists, requires prior specific permission and/or a fee. Copyright 2018 SBC.

IHC 2018, Anais Estendidos do XVII Simpósio Brasileiro sobre Fatores

Humanos em Sistemas Computacionais

Outubro 22-26, 2018, Belém, Brasil

PÔSTERES VIRTUAIS E DEMOS todos os contextos, sendo necessário um direcionamento na seleção das ações adequadas. Esta pesquisa propõe a criação de personas para delinear o perfil de alunas da Universidade Federal do Ceará (UFC) no campus de Russas, onde um projeto visa fortalecer a participação e engajamento feminino nos cursos de TI. A motivação surgiu a partir da percepção de que as alunas possuem diferentes necessidades e desafios na vida acadêmica e que as ações devem alcançar os diferentes perfis de alunas existentes em um contexto.

\section{TRABALHOS RELACIONADOS}

Leme et al. [2] utilizaram a técnica de personas para delinear os diferentes perfis de idosos que utilizam o Facebook, suas motivações e dificuldades de interação. Rodrigues et al. [5] definem personas para caracterizar o público alvo de aplicações terapêuticas para a saúde mental e com isso orientar o design das aplicações. Observa-se que a criação de personas pode orientar o design de produtos e serviços a determinado público alvo. Pesquisas por meio de questionários vêm sendo conduzidas para identificar os desafios de alunas de graduação [3], porém não foi observado o uso da técnica de personas como meio de utilizar os resultados das pesquisas para orientar ações futuras direcionadas às alunas respondentes.

\section{METODOLOGIA DE PESQUISA}

Esta pesquisa faz parte do projeto de pesquisa e extensão "Meninas Digitais do Vale" que busca fortalecer a participação feminina em cursos de Ciência da Computação e Engenharia de Software do campus da UFC em Russas. Uma pesquisa por meio de questionário foi conduzida para traçar os perfis das alunas do campus. Os questionários foram criados pelas alunas que participam do projeto e pela professora coordenadora do projeto. $\mathrm{O}$ questionário buscava identificar o perfil demográfico das alunas (nome, idade, estado civil e renda familiar), os fatores que influenciaram a escolha do curso, as suas experiências universitárias, a área em que pretendem atuar, se já sofreram ou presenciaram algum tipo de preconceito e se o fato de serem mulheres já influenciou a sua vida acadêmica. Também foram investigados fatores que podem influenciar na desistência do curso e sua percepção sobre os seus talentos e pontos que gostariam de melhorar. Os questionários foram aplicados presencialmente em todas as salas dos cursos de TI do campus pelas mesmas alunas que o elaboraram, 89 das 106 alunas do campus que fazem cursos de TI responderam. Com 
os resultados foram criadas três personas com base em características comuns entre as alunas. Os questionários foram divididos em três grupos, para traçar o perfil das alunas ingressantes $\left(1^{\circ}\right.$ e $2^{\circ}$ semestres $)$, alunas veteranas $\left(3^{\circ}\right.$, $4^{\circ}$ e $5^{\circ}$ semestres $)$ e alunas finalistas $\left(6^{\circ}, 7^{\circ}\right.$ e $8^{\circ}$ semestres $)$. Com base nas tendências identificadas nas respostas em cada um dos três grupos, foram criadas as personas.

\section{PERSONAS IDENTIFICADAS}

Para a criação das personas, foram considerados o perfil demográfico, a situação acadêmica, expectativas sobre a área, seus talentos e necessidades. As informações a serem apresentadas nas personas foram definidas por serem relevantes para direcionar as ações do projeto. A Figura 1 ilustra as personas identificadas. A primeira persona apresenta características de uma aluna de $1^{\circ}$ semestre, chamada Maria Helena, com 18 anos de idade e renda familiar de um salário mínimo. Maria Helena já sofreu preconceito e nunca se sentiu favorecida por ser mulher. Indica como seus talentos o rápido aprendizado, a organização e a comunicação. Como pontos a melhorar, ela indica a timidez, o nervosismo e o foco. Ela escolheu a Engenharia de Software devido à possibilidade de trabalhar com novas tecnologias e à oportunidade de criar aplicativos.

A segunda persona é Ana Rita, aluna do $4^{\circ}$ semestre, possui 20 anos de idade e renda familiar de três salários mínimos. Ela também já sofreu preconceito e nunca se sentiu favorecida por ser mulher. Possui talentos como a persistência, a liderança e o rápido aprendizado. Deseja melhorar a ansiedade, a paciência e a organização. Ela possui experiências acadêmicas com iniciação acadêmica, participação de eventos científicos e monitoria. A terceira persona é Maria Luiza, aluna de $7^{\circ}$ semestre, com 22 anos de idade e renda familiar de um salário mínimo. Ela já sofreu preconceito e nunca se sentiu favorecida por ser mulher. Como seus talentos, indica a determinação, a criatividade e o rápido aprendizado. Deseja melhorar a programação, a ansiedade e a organização. Pretende atuar nas áreas de Engenharia de Software e IHC.

\section{CONSIDERAÇÕES FINAIS E TRABALHOS FUTUROS}

As personas permitiram definir um conjunto inicial de ações no campus, como fóruns, palestras, oficinas e experiências com jogos proporcionando um melhor ambiente para o fortalecimento e empoderamento das mulheres. As personas foram determinantes na análise das necessidades das alunas e no planejamento estratégico de ações que iniciaram em agosto de 2018. Como trabalhos futuros, pretende-se validar as personas com o público alvo e explorar outros critérios para a criação de personas em um mesmo grupo, enriquecendo a análise dos dados.

\section{REFERÊNCIAS}

1. Gisela Cesário, Nélya G. Silveira, Silvia A. Bim, Cristiano Maciel. 2017. Por Mais Mulheres na Computação: análise dos trabalhos publicados no $\mathrm{X}$ Women in Information Technology. In Proc. of Women in Information Technology, 1213-1217.

2. Ricardo Leme, Luciana Zaina, and Vitor Casadei. 2015. Um estudo da interação do público da terceira idade com o Facebook em dispositivos móveis: identificação e definição das personas. In Proc. of the Brazilian Symposium on Human Factors in Computing Systems, 53-62.

3. Fabíola Nakamura, Ludymila Lobo, Rosiane de Freitas, et al. 2017. Participação feminina em cursos de computação: um estudo no Instituto de computação da Universidade Federal do Amazonas. In Proc. of Women in Information Technology, 1233-1237.

4. John Pruitt and Jonathan Grudin. 2003. Personas: practice and theory. In Proc. of the Conference on Designing for user experiences (DUX '03), 1-15.

5. Kamila R. H. Rodrigues, Lucas F. Bocanegra, Vinícius P. Gonçalves, et al. 2014. Enriquecimento de personas para apoio ao design de aplicações terapêuticas para a saúde mental. In Proc. of the Brazilian Symposium on Human Factors in Computing Systems, 51-60.

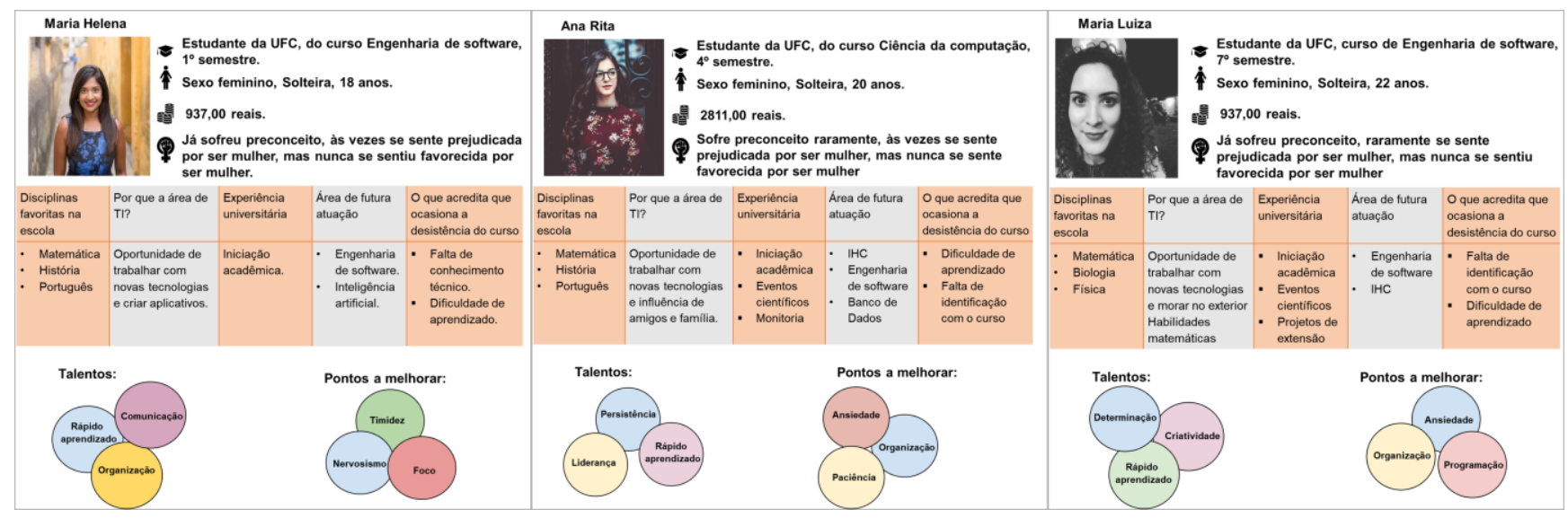

Figura 1. Personas identificadas por meio da pesquisa. 